\title{
Internacionalistas entre la revolución y el fascismo: la Unión General de Trabajadores en el mundo (1919-1936)*
}

\author{
Manuela Aroca Mohedano ${ }^{1}$ \\ Fundación Francisco Largo Caballero \\ Universidad Carlos III de Madrid
}

RESUMEN: El artículo analiza la política exterior que desarrolló UGT de España, en el marco del internacionalismo obrero, durante el periodo de entreguerras. Se ha consultado documentación del Instituto de Historia Social de Ámsterdam, documentación de las Fundaciones Francisco Largo Caballero y Pablo Iglesias, así como abundante documentación de hemeroteca.

Metodológicamente, se basa en la comparación entre los documentos de las Internacionales y los que elaboró la central sindical española, referidos a cuestiones exteriores.

Entre 1919 y el estallido de la guerra civil española, se estabiliza el mundo internacional obrero, al que los ugetistas españoles se incorporaron en la creencia de que el internacionalismo sería eficaz para solucionar grandes problemas. Los acontecimientos fueron demostrando la impotencia de las organizaciones obreras a la hora de enfrentarse a los grandes desafíos de las décadas de los años veinte y treinta.

\footnotetext{
* Este artículo ha sido elaborado en el marco del proyecto de I + D, HAR2013-44849-P, «La trayectoria internacional del sindicalismo socialista español (1888-1986)», del Ministerio de Economía y Competitividad de España, del Programa Estatal de Investigación Científica y Técnica de Excelencia, concedido a la Fundación Francisco Largo Caballero.

Archivos consultados: Fundación Pablo Iglesias, Alcalá de Henares, Madrid, (FPI), fondos: Archivo Amaro Rosal Díaz (AARD), Archivo Histórico (AH) y Archivos Varios (AAVV).

Fundación Francisco Largo Caballero, Alcalá de Henares, Madrid, (FFLC).

International Institut of Social History, Ámsterdam (IISH), fondo: International Federation of Trade Unions (IFTU).

1 maroca@cec.ugt.org, maroca@hum.uc3m.es, ORCID iD: https://orcid.org/0000-00025848-1674.
} 
UGT acudió al internacionalismo para justificar la estrategia reformista que el sindicato había adoptado en el interior. Durante el bienio negro, contribuyó a radicalizar la posición de líderes y militantes. El artículo pretende demostrar que la política exterior fue, en todo este tiempo, muy influyente en la línea estratégica que adoptó el sindicato en el interior de España.

\title{
PALABRAS CLAVE: sindicalismo; UGT; internacionalismo; periodo de entreguerras; FSI; OIT.
}

\section{Internationalism between revolution and fascism: the Spanish Unión General de Trabajadores (UGT) in the world (1919-1936)}

\begin{abstract}
The article analyses the approach to external affairs adopted by Spain's Unión General de Trabajadores (UGT) during the interwar period, within the proletarian internationalist framework. The documents consulted are from the International Institute of Social History in Amsterdam, the Francisco Largo Caballero Foundation and the Pablo Iglesias Foundation. A large number newspaper archives were also examined.

Documents on external affairs produced by the Internationals and the Spanish Trade Union Confederation are compared methodologically.

The period between 1919 and the outbreak of the Spanish Civil War saw the stabilization of the international labour landscape. UGT leaders were convinced that internationalism was the best way to solve major problems. Events showed workers' organizations to be powerless to face the major challenges arising in the Twenties and Thirties.

UGT looked to internationalism to justify the reformist strategy it had adopted at home. During the Black Biennium, it contributed to the radicalization of leaders and activists. The article seeks to show that external policy was very influential on the strategic line adopted by the Union inside Spain throughout this time.
\end{abstract}

KEY WORDS: unionism; Unión General de Trabajadores (UGT); internationalism; interwar period; IFTU; ILO.

CÓMO CITAR ESTE ARTíCULO/CITATION: Aroca Mohedano, Manuela, «Internacionalistas entre la revolución y el fascismo: la Unión General de Trabajadores en el mundo (1919-1936)», Hispania, 78/259 (Madrid, 2018): 323-352. https://doi.org/10.3989/ hispania.2018.008.

La historia de las relaciones internacionales ha experimentado, en los últimos tiempos, importantes modificaciones. Junto a los estados, han aparecido otros actores internacionales que, en el campo social o en el campo político, se han convertido en objeto de análisis. Es el caso de las relaciones de partidos y sindicatos con organismos supranacionales o de las conexiones bilatera- 
les con otras organizaciones nacionales extranjeras. Puesto que los actores sociales y políticos tienen una entidad en esencia nacional, el análisis de su actuación en el escenario internacional ha sido, por lo general, infravalorado. Al mismo tiempo, su estudio entraña serias dificultades metodológicas. Sin embargo, investigaciones recientes están atribuyendo valor a la acción internacional de los agentes sociales ${ }^{2}$. En este sentido, el presente artículo trata de valorar de qué manera se incorporó el sindicato socialista español, Unión General de Trabajadores (UGT), a la red de relaciones internacionales del movimiento obrero durante el periodo de entreguerras, y de qué manera esta incorporación resultó fundamental para el desarrollo de su acción sindical nacional.

El profesor Andrea Ciampani ha establecido un triple nivel de incardinación de los sindicatos en la acción internacional: un primer estadio, definido como el periodo del internacionalismo; las relaciones diplomáticas; y las relaciones internacionales. En el primero encontramos el intento de los actores sociales de crear una red de conexiones internacionales, en principio, de carácter informativo, que permitiera una interacción de las políticas nacionales. Se corresponde a la creación de los grandes organismos supranacionales sindicales: Federación Sindical Internacional (FSI) y Segunda Internacional Socialista; en segundo lugar, las relaciones diplomáticas alcanzan su configuración cuando los estados, después de la Primera Guerra Mundial, atribuyen al mundo del trabajo un lugar destacado de la recomposición de las estructuras internacionales, al crear un organismo especializado en las relaciones del trabajo, en el que interactúan gobiernos, sindicatos y patronal y es parte sustancial de la reconstrucción de posguerra; el último estadio, el de las relaciones internacionales integra la totalidad de las relaciones bilaterales entre sindicatos de todo el mundo ${ }^{3}$.

El periodo que abarca desde la Primera Guerra Mundial hasta la guerra civil española, con sus problemáticas y sus avances en el terreno sindical, permitió a UGT incorporarse a este triple nivel de relaciones y establecer mecanismos de actuación que tuvieron repercusión en la trayectoria y la evolución, no solo del sindicato español, sino también del conjunto del país, dada la fuerte influencia social que UGT fue adquiriendo durante este periodo.

La Primera Guerra Mundial desató una conmoción en las estructuras del movimiento obrero y rompió uno de los principios básicos sobre los que se había asentado la teoría política de partidos y sindicatos: la concepción inter-

2 Destaca el grupo de investigación dirigido por el profesor Andrea Ciampani, de la Universidad LUMSA de Roma, o los trabajos de Sigfrido Ramírez.

3 Andrea Ciampani, «I sindacati europei e le relazioni social internazionali», conferencia pronunciada en el Seminario Internacional «Il sindacato come attore delle relazioni internazionali. Il caso spagnolo (1919-1990)», Roma, 13 al 14 de diciembre de 2016. 
nacionalista. Tras la finalización del conflicto, las organizaciones se dispusieron a restañar las heridas. Pero el triunfo de la revolución soviética constituyó un nuevo elemento de división. Los movimientos socialistas se enfrentaron entonces a la necesidad de escoger entre reforma o revolución, como principio estratégico, y esta elección no fue solo de ámbito nacional, sino que tuvo fuertes repercusiones internacionales.

En España, la central socialista UGT vivió estas convulsiones. Su acción sindical nacional se vio influida por ellas, al mismo tiempo que la pertenencia a los organismos supranacionales prestó legitimación y soporte a sus políticas sindicales.

UGT se incorporó sin reservas a la recomposición de la FSI, que obtuvo una mayor autonomía respecto a la Internacional política (Segunda Internacional). Los socialistas españoles apoyaron también la idea de crear y sostener un organismo internacional, dependiente de la Sociedad de Naciones, que se ocupara específicamente del mundo del trabajo. Con su respaldo a la Organización Internacional del Trabajo (OIT) y la designación de líderes ugetistas como representantes de la clase trabajadora española, se certificaba la incorporación de la central a un nuevo escenario, en el que los gobiernos asumían la negociación con empresarios y trabajadores como puntal básico para la reconstrucción de las estructuras económicas.

\section{UN SINDICATO REFORMISTA EN CLAVE INTERNACIONAL}

La constitución de la Tercera Internacional transformó los principios del internacionalismo y convirtió en irreversible la fractura del movimiento obrero. En 1921, se creaba la Internacional Sindical Roja (ISR) de Moscú, que, al igual que en el plano político había hecho la Comintern, fraccionaba la unidad internacional, en este caso del sindicalismo de inspiración socialista.

La división en dos internacionales políticas socialistas procuró un mayor protagonismo a la FSI que asumió, en parte, el papel unificador y centralizador que antes había tenido la Segunda Internacional. La FSI aceptó, entonces, los principios de la Sociedad de Naciones y la reconstrucción del orden burgués. Las organizaciones obreras trabajarían en su seno para crear progresivamente una sociedad socialista. Pero la Internacional no pudo sustraerse ideológicamente a lo que estaba sucediendo en Rusia ${ }^{4}$.

Hasta 1922, el Partido Socialista Obrero Español (PSOE) atravesó un periodo de vacilaciones: apoyó diversas posiciones políticas que iban desde la propuesta de la reunificación de las dos Internacionales a la entrada en la

\footnotetext{
4 Recomendaciones al Congreso de la FSI, IISH, IFTU, inventario $\mathrm{n}^{\circ} 7$.
} 
Comintern. Para despejar dudas, los socialistas españoles decidieron en su Congreso Extraordinario de junio de 1920, enviar a dos representantes del PSOE a Rusia, para valorar la experiencia soviética, Fernando de los Ríos y Daniel Anguiano.

La valoración de Fernando de los Ríos sobre la acción sindical del nuevo régimen fue muy negativa y prevaleció sobre la más favorable de Anguiano: los sindicatos en Rusia, tras establecerse la centralización del Estado y la instauración de un régimen jerárquico y autoritario, se habían visto desposeídos de toda función real, ya que no podían plantear protestas o negociaciones. Tampoco se había otorgado al sindicato un papel director en la economía: se convertía solo en un «flácido órgano burocrático». Su función principal consistía en movilizar la fuerza de trabajo para transformarla en un ejército laboral, imprescindible para el desarrollo del régimen ${ }^{5}$.

La vinculación de UGT con la recién reconstruida FSI, instalada en Ámsterdam, se sustentaba sobre sólidos lazos. Además, el trabajo del representante ugetista, Largo Caballero, en las Conferencias de la OIT mostró nuevas posibilidades para la mejora de las condiciones de los trabajadores. Como consecuencia, UGT tuvo pocas dudas sobre su adscripción y estrategia internacional. Esta línea fue ratificada en su XIV Congreso, celebrado en junio de 1920, a pesar de que las decisiones de ámbito internacional se vieron condicionadas por la resolución que en ese momento obligaba al partido hermano a explorar la entrada en la Tercera Internacional.

Aunque la mayoría del sindicato apoyó la posición de Largo Caballero, un sector de la militancia cuestionó el apoyo que las instituciones socialistas estaban prestando a la reconstrucción general del orden liberal, al vincularse a la Sociedad de Naciones y a sus organismos. La cuestión internacional estaba relacionada de manera estrecha con la estrategia general del sindicato y lo que se dirimía, a efectos prácticos, era la continuidad del trabajo en el Instituto de Reformas Sociales. Durante el año 1921, la dirección de UGT hizo una defensa de su papel en el mundo internacional, que llevaba implícita una defensa de su estrategia en el interior del país. Largo Caballero consideraba irreal la tradicional división entre «reformistas» y «revolucionarios», pero defendió su trabajo en el seno de la OIT y, en consecuencia, una estrategia reformista ${ }^{6}$.

En el conflicto generado por la división de las internacionales, UGT fue la organización socialista española que antes solucionó la división. El protagonismo del sindicato fue decisivo a la hora de escorar a las organizaciones socialistas hacia el ámbito internacional socialdemócrata, abandonando toda pretensión de adhesión a los principios del comunismo soviético.

5 DE LOS RÍOS, 1994: 95-96.

6 Acta de la reunión de la CE del Comité Nacional de UGT, 17-12-1921, FPI, AARD, 253-1. 
Por el contrario, los anarquistas españoles dieron su apoyo a la creación de la Internacional Sindical de Moscú. Su Primer Congreso Constituyente se celebró el 3 de julio de 1921. Al encuentro acudieron los anarquistas españoles Hilario Arlandis, Joaquín Maurín, Jesús Ibáñez y Andreu Nin, dadas las simpatías con que los cenetistas contemplaban el nacimiento de la ISR, a la que se afiliarían durante un breve periodo de tiempo. En 1922, después de ser encarcelado en Berlín, Andreu Nin llegó a Rusia, donde fue nombrado miembro de su Secretariado ${ }^{7}$.

Como consecuencia, la cuestión internacional interfirió sobre otro proceso de gran calado en España: el intento de unidad de las centrales sindicales. Ese proceso se había puesto en marcha en 1918 y en 1920 se daba por fracasado. Las diferencias estratégicas en el panorama internacional eran evidentes: mientras UGT había decidido en Congreso la permanencia en la FSI, la Confederación Nacional del Trabajo (CNT) había optado por su integración en la futura ISR o Profinterm, en proceso de creación. En 1920, UGT y CNT aducían la dificultad añadida de la pertenencia a dos internacionales para justificar la paralización del acercamiento ${ }^{8}$.

En febrero de 1921 nació la conocida como Segunda Internacional y Media, a propuesta del Partido Socialista Austriaco, con sede en Viena. Tenía la misión de representar a las organizaciones que admitían que la Segunda Internacional Socialista había quedado completamente desacreditada después de la Primera Guerra Mundial, pero no compartían las posiciones de Moscú. Su nacimiento planteaba a los socialistas españoles una nueva disyuntiva.

Las críticas contra los comunistas, escindidos de las organizaciones socialistas, se fueron haciendo cada vez más duras. El propio Largo Caballero acusó a los revolucionarios rusos de querer dirigir la actuación de los organismos obreros del resto del mundo. La estrategia, según Caballero, había sido la división y subdivisión de los organismos hasta debilitar el socialismo, colocando a las organizaciones en situación de impotencia para hacer frente a sus problemas nacionales ${ }^{9}$.

En 1922, la FSI envió a Jan Oudegeest y Leon Jouhaux como representantes al XV Congreso de UGT. Era necesario extremar la identificación entre ambas organizaciones. En ese mismo congreso, un enfrentamiento entre partidarios de las tesis proterceristas y defensores de la FSI se saldó con un muerto, por arma de fuego, el albañil y militante socialista González Gordillo. Otros tres hombres resultaron heridos ${ }^{10}$. El incidente provocó la expulsión de

7 NIN, 1978. PAGÉS, 1975.

8 Acta de la reunión de la CE del Comité Nacional de UGT celebrada en Madrid, 2-091920, FPI, AARD, 253-1.

9 Francisco Largo Caballero, «Hacia otro fracaso», El Socialista, 17-8-1921: 1.

10 «Un muerto y tres heridos en la Casa del Pueblo», $A B C, 22-11-1922: 15$ y «La verdad sobre el suceso sangriento», El Socialista, 24-11-1922: 2. 
los comunistas de UGT. Se zanjaba así la cuestión de las internacionales en el sindicato. UGT continuaría definitivamente adherida a la $\mathrm{FSI}^{11}$. Se hablaba de la necesidad de continuar el trabajo en la OIT, en colaboración estrecha con la FSI. Comenzaba una etapa de incuestionable identificación con los postulados de la Internacional de Ámsterdam, bajo el sello del protagonismo de Largo Caballero, con el fuerte apoyo intelectual y la presencia de Julián Besteiro.

Los socialistas españoles habían resuelto el problema, pero la situación no era tan clara en la propia FSI. En la Internacional de Ámsterdam se formó, en torno a 1923-1924, una sección izquierdista cercana al antiguo secretario Edo Fimmen, líder de la Federación Internacional de Trabajadores del Transporte, y del núcleo de dirección del Trade Union Congress. La consecuencia más importante fue la creación, en 1925, de un comité sindical anglo-ruso, que intentó trabajar dentro de la FSI por la unidad de ambas internacionales ${ }^{12}$. La experiencia concitó una frontal oposición de la Unión General de Trabajadores ${ }^{13}$.

La FSI convocó un Congreso extraordinario, que se celebró en Londres, entre el 22 y el 27 de noviembre de 1920: 17 naciones, 24.616.000 trabajadores representados y 19 federaciones internacionales de industria. UGT estuvo representada por Julián Besteiro y Francisco Largo Caballero, que integraron, además, la Comisión ponente sobre la resolución de «socialización de los medios de producción ${ }^{14}$.

En ese Congreso, el británico J.H. Thomas fue ratificado como presidente, al mismo tiempo que Jouhaux y Mertens y el alemán Leipart eran nombrados vicepresidentes ${ }^{15}$. Con la elección de este último se rehabilitaba definitivamente al sindicalismo alemán en la línea de dirección mundial. Finalmente, los secretarios serían Oudegeest y Fimmen. Largo Caballero era nombrado miembro de la delegación del Comité director de España y Portugal ${ }^{16}$.

Besteiro realizó en ese encuentro una extensa intervención para hacer pública la persecución contra la clase trabajadora española por parte de su gobierno. Las garantías constitucionales llevaban dos años suspendidas. Se perseguía sistemáticamente a las organizaciones sindicales y a sus militantes.

11 Memoria y orden del día del XV Congreso de UGT, FPI, fot. 31.

12 VAN GOETHEM, 2006: 38.

13 Acta de la reunión de la CE de UGT, 12-05-1925, FPI, AARD, 253-3. La ejecutiva de UGT se opuso unánimemente a la celebración de una conferencia de la FSI con la Sindical Roja, sugiriendo que se respetaran los acuerdos adoptados tanto en los congresos como en el comité director. Acta de la reunión de la Comisión Ejecutiva de UGT, 21-11-1925, FPI, AARD, 253-3.

14 Memoria y orden del día del XV Congreso de UGT, FPI, fot. 31.

15 «Premier rapport sur l'activité de la Fédération Syndicale (juillet 1919-decembre 1921), presenté au Congrés Ordinaire de Roma, abril 1922», Le mouvement syndical international, suplement V, abril 1922: 11, IISH.

${ }_{16}$ Memoria y orden del día del XV Congreso de UGT, FPI, fot. 31. 
Denunció la existencia de un terrorismo gubernamental y reaccionario, frente al llamado «terrorismo» de las organizaciones obreras y demandó el envío de una misión de encuesta para valorar la situación en nuestro país. Pero el Congreso no dio respuesta ${ }^{17}$.

UGT amplió la información suministrada por Besteiro con un informe, firmado por Largo Caballero, que fue posteriormente enviado al director de la OIT. El dosier repasaba los procesos huelguísticos, el recuento de muertos, heridos y desterrados y aportaba pruebas del grado de imperfección del régimen democrático español ${ }^{18}$.

Apenas unos días después de la entrega del informe, FSI se dirigía directamente al jefe del Gobierno español, Eduardo Dato, mediante una carta firmada por Jouhaux y Oudegeest, para trasladarle «su protesta contra la violación sistemática de las libertades y los derechos sindicales». Recordaba al gobierno que su adhesión a la OIT le obligaba a cesar en la persecución de los derechos de los trabajadores, respetando el derecho de organización y de defensa obrera ${ }^{19}$. La carta nunca fue contestada, aunque, según los líderes sindicales españoles, tuvo su efecto y consiguió que disminuyera la represión ${ }^{20}$. La Internacional propuso entonces enviar a España una comisión para recoger datos sobre el terreno. Sin embargo, UGT declinó la oferta, objetando la situación de inseguridad que se vivía en el país. En la reunión del Comité de la FSI celebrada los días 21 y 22 de octubre de 1921, a la que asistió Caballero como miembro de ese organismo, se señaló en el orden del día un punto especial sobre la situación de la organización obrera de España y se adoptó por unanimidad la proposición del representante de Inglaterra para otorgar al Comité de la Internacional Sindical un voto de confianza para apoyar a España en todo lo posible. Aunque la Internacional continuó insistiendo en su intención de enviar una comisión, la dirección de UGT evitó que esta circunstancia pudiera producirse.

La impresión sobre el Congreso de Londres que obtuvieron Besteiro y Largo Caballero fue que la FSI había conseguido configurarse como una magnífica fuerza. Habían quedado aisladas las opciones más conservadoras, representadas por los delegados canadienses, que se acercaban más a los ausentes americanos que a los representantes de los sindicatos europeos. Mientras, en opinión de los líderes españoles, italianos y noruegos mantuvieron

17 «Compte rendu du Congrès Syndical International Extraordinaire tenu a Londres du 22 au 27 de novembre de 1920», Le Mouvement Syndical International, suplément IV, mars 1922: 23-25, IISH.

18 CUESTA BUSTILLO, 1997: 295-327.

19 «Carta de la Internacional sindical al jefe del gobierno español», El Socialista, 10-121920: 1 .

20 «El Congreso Sindical Internacional de Roma», El Socialista, 10-05-1922: 1. 
una oposición extremista, cercana a postulados revolucionarios. Pero Largo Caballero consideraba que UGT debía prestar «un gran cariño» a la FSI, que llegaría un día a ser temible para los adversarios de los trabajadores ${ }^{21}$. Los líderes de UGT descartaron también el ofrecimiento de la FSI de organizar una colecta de fondos para España, al considerar que la situación en Hungría, por ejemplo, era mucho peor. Por esa circunstancia, esperaban que la Internacional se limitara a enviar unos pequeños auxilios con cargo a su caja ${ }^{22}$.

La Internacional sindical no soslayó la toma de partido en los problemas económicos de posguerra. En sus resoluciones, dejó claro que no se podía reconstruir Europa en base únicamente al esfuerzo de Alemania. Por primera vez, se hablaba de la necesidad de que las centrales sindicales ejercieran su poder sobre sus respectivos gobiernos nacionales para obligarles a negociar y a entenderse, ratificando así la vía del reformismo como estrategia.

Los encuentros de Londres (1920) Ámsterdam (1921) y Génova (1922) demostraron que la FSI había tomado posiciones claras y daban cuenta de que el internacionalismo parecía estar superando a buen ritmo las rupturas que la guerra había causado. Las decisiones políticas habían sido una parte importante de la acción de la FSI: había decretado el boicot al gobierno húngaro de Horthy y había realizado gestiones en todos los ámbitos a su alcance para impedir la intervención de las potencias occidentales contra la Rusia soviética. En este sentido, destinó sus esfuerzos en la movilización de los obreros contra el transporte de material de guerra a Polonia y reunió a las federaciones internacionales de mineros, transportistas y metalúrgicos para tratar de coordinar una posible huelga general como respuesta en caso de guerra. Por otra parte, había convocado a las mujeres de los sindicatos de orientación socialista, constituyendo una sección específica de la Internacional para las mujeres ${ }^{23}$.

En estos años, se consolidó una cada vez mayor implicación del sindicato socialista español en las cuestiones internacionales y un relativo aumento del protagonismo de sus representantes, estimulado por el papel que Largo Caballero y su equipo estaban desarrollando en las conferencias de la OIT. Fueron años de defensa de las posiciones reformistas en el ámbito internacional, que permitieron a Julián Besteiro y Francisco Largo Caballero conocer de primera mano las consecuencias del triunfo de los primeros regímenes fascistas en Europa.

La posible ocupación del Rhur fue otra de las cuestiones que la FSI abordó en su siguiente congreso, donde adoptó la resolución de contrarrestar esta acción, si llegaba a producirse, convocando una huelga general. Era la prime-

21 Reunión del pleno del Comité Nacional de UGT, 4-01-1921, FPI, AARD, 259-1.

22 Reunión del Pleno del Comité Nacional de UGT, 16-01-1922, FPI, AARD, 259-1.

23 Documentación relativa al Congreso de la FSI celebrado en Londres, 1922, IISH, IF$\mathrm{TU}$, inventario $\mathrm{n}^{\mathrm{o}} 8$. 
ra vez que en un congreso sindical internacional se hablaba de lucha contra el fascismo $^{24}$.

Para tratar de los problemas relacionados con la paz, la FSI convocó la Conferencia de La Haya. En el encuentro se instó a los españoles a convertirse en mediadores con América Latina. Largo Caballero intervino para abogar por una alianza de organizaciones sindicales latinoamericanas, en el seno de la FSI, que España tendría la obligación moral de liderar ${ }^{25}$. El líder manifestó su disposición a apoyar una huelga general en España, en caso de que fuera invadida la cuenca del Ruhr, en solidaridad con los trabajadores alemanes. Aunque Largo Caballero consideraba que la acción española para impedir una guerra era limitada, debido al escaso desarrollo industrial de nuestro país, la intervención española sería importante insistiendo cerca de los sindicatos de los países hispanoamericanos para atraerlos a la $\mathrm{FSI}^{26}$. UGT nunca contempló liderar los países del arco sur de Europa. Más que la cercanía geográfica, valoraban la cercanía humana, histórico-cultural y social con los trabajadores de Iberoamérica $^{27}$. Se propuso convertirse en mediadora entre la FSI y el sindicalismo americano, lo que le permitiría incrementar su influencia en la Internacional.

El XV Congreso, en 1922, había mandatado a la dirección de UGT para organizar una conferencia en Madrid, con el objetivo de propiciar el acercamiento de las representaciones de todos los organismos obreros de América Latina, Portugal y España, cuyos acuerdos deberían ser sancionados por la Internacional de Ámsterdam ${ }^{28}$. La aspiración era crear una Regional dentro de la FSI, a través de la cual podría obtener su particular espacio de influencia.

Existían contactos con algunos sindicatos latinoamericanos, pero, en general, eran débiles y se limitaban al intercambio de informaciones puntuales, sobre huelgas, boicots, asuntos relacionados con el trabajo de los emigrantes, etc. En agosto de 1920, la dirección había dado vía libre al intento de organización de la Conferencia Iberoamericana en Madrid. Por las mismas fechas, el Comité Internacional del Trabajo en la Liga de las Naciones «se congratulaba de la resolución adoptada por el Congreso al pretender crear la Federación Iberoamericana, tanto por las facilidades para conocer mejor las actuaciones de los obreros de los diversos países, cuanto por la influencia que España pueda tener entre los trabajadores de la América Latina» ${ }^{29}$.

${ }^{24}$ Résolution sur le reaction mondiale, IISH, IFTU, inventario $\mathrm{n}^{\mathrm{0}} 8$.

25 Antonio Fabra Ribas, «El Congreso Mundial de la Paz. Las modernas tendencias del movimiento obrero», El Socialista, 4-01-1923: 1.

26 «Discurso de Largo Caballero en el Congreso Mundial de la Paz», MARTÍN NÁJERA Y GARRIGÓS, 2003, vol. 2: 531-534.

27 RUBIO, 1989: 117-207.

28 LARGO CABALLERO, 1997: 222-224.

29 Actas de la reunión de la CE del Comité Nacional de UGT, 2-09-1920 y 14-10-1920, FPI, AARD, 253-1. 
Sin embargo, en el mes de noviembre los argentinos planteaban que su posición sería favorable a un entendimiento, solo si en la conferencia se aceptaban los principios de la III Internacional ${ }^{30}$. Pronto la Federación Obrera Regional Argentina manifestó que no estaba de acuerdo en que se desarrollara la Conferencia en Madrid, por su orientación favorable a las directrices de lo que los comunistas consideraban la Internacional amarilla de Ámsterdam ${ }^{31}$.

Uno de los países con los que más se estrecharon las relaciones fue México. La llegada a la presidencia mexicana del general Calles y su intensificación de la reforma agraria, las leyes sociales promulgadas y el apoyo a las clases obreras fueron vistos por los socialistas españoles como una nueva oportunidad para extender la influencia por el continente latinoamericano ${ }^{32}$. En el ámbito sindical, los acercamientos entre centrales se habían materializado por impulso de los contactos personales. Largo Caballero y el líder sindical Vicente Lombardo Toledano habían coincidido en las Conferencias de la OIT, donde el líder mexicano representaba a la Confederación Revolucionaria Obrera Mexicana (CROM). El socialismo mexicano promovió entre sus afiliados el reconocimiento de las organizaciones homónimas españolas, y el propio Toledano preconizó la necesidad de priorizar el contacto con los socialistas europeos sobre las relaciones con el sindicalismo norteamericano ${ }^{33}$. Pero los contactos quedaron sin respaldo institucional hasta que, algunos dirigentes de la CROM, entre ellos el propio Vicente Lombardo, fundaron la Confederación de Trabajadores de México (CTM), en 1936, ya en los prolegómenos de la guerra civil española ${ }^{34}$. La integración de la CTM en la FSI desde su fundación permitiría otras vías de contacto, pero esa era ya otra época en la historia de las organizaciones sindicales españolas.

Por otra parte, las relaciones de los sindicatos latinoamericanos habían estado históricamente mediatizadas por el intento de la American Federation of Labor (AFL) norteamericana de controlar ese espacio. Además de los norteamericanos, UGT, en su intento de liderazgo, iba a tener otro directo competidor: la Profintern. La obra del español Andreu Nin fue, en este ámbito, decisiva $^{35}$. Las gestiones de la Internacional comunista dieron sus frutos y a finales de esa misma década, en 1929, se constituía la Confederación Sindical Latinoamericana en Montevideo, bajo los auspicios de la ISR. Celebraba su

30 Acta de la reunión de la comisión ejecutiva de UGT, 4-11-1920, FPI, AARD, 253-1.

31 Acta de la reunión de la CE del Comité Nacional de UGT, 16-12-1920, FPI, AARD, 253-1.

32 Andrés Saborit, «Un viaje de Albert Thomas. América y la Oficina Internacional del Trabajo», El Socialista, 3-06-1925: 1.

33 MATEOS, 2016: 242-267.

34 SPENSER, 2016.

35 KOCHANSKI, 1988: 249-295. 
Primera Conferencia Sindical Latinoamericana en Buenos Aires en junio de ese mismo año ${ }^{36}$.

Pese al esfuerzo y al intento de aprovechar el foro de la OIT para tratar de consolidar un espacio sindical latinoamericano vertebrado por el sindicato español, el proyecto de constituir y liderar una sección regional de la FSI nunca llegó a ser más que un lejano sueño. UGT continuó teniendo una influencia marginal, a pesar de que consolidó la representación de Largo Caballero en el Comité de la FSI, en nombre de España y Portugal, en el Congreso de Viena de 1924, con Andrés Saborit como suplente ${ }^{37}$.

Durante el periodo de entreguerras, la acción que UGT desarrolló en el seno de la OIT fue también decisiva para los asuntos internos del sindicato. En 1920, Jan Oudegeest dirigía el Grupo de los trabajadores de la OIT, bajo las directrices que marcaba la FSI.

En el interior de esa institución se desarrolló una pugna de los representantes de los trabajadores contra el Gobierno de Dato, como consecuencia de la persecución que estaban sufriendo las dos grandes centrales españolas. El director de la OIT, Albert Thomas apoyó la posición de UGT frente a la del Gobierno español, pero recomendó a la central socialista la ruptura de las negociaciones abiertas con CNT de cara a un futuro proceso de unificación. La decisión del director de la OIT de publicar el informe presentado por Largo Caballero en 1920, acusando al Gobierno español de incumplir los acuerdos derivados de la adhesión a la Sociedad de Naciones, suscritos en el ámbito internacional ${ }^{38}$, terminó con la dimisión del representante gubernamental ante la OIT, vizconde de Eza.

El resultado de la crisis se interpretó como un triunfo de UGT, con el apoyo del sindicalismo internacional. Al mismo tiempo, durante ese periodo se produjo el acercamiento de Fabra Ribas, socialista y ugetista, al Buró de la OIT. A partir de diciembre de 1921, se convirtió en corresponsal de la OIT para España, Portugal y América Latina. Fabra trabajó también para propiciar el establecimiento de una identidad hispano-americana, nunca alcanzada, en el seno de la OIT.

36 BECKER, 2013: 229-270.

37 Report on the activities of the International Federation of Trade Unions during the years 1922 and 1923. Submitted to the Third Ordinary Congress Vienna, June 1924, Amsterdam, IISH, IFTU (s/f): 268.

38 CUESTA BUSTILLO, 1994: 109 y ss.; 1997: 163 y ss. 


\section{EL MUNDO OBRERO INTERNACIONAL, ENTRE FASCISMOS Y PROYECTOS DE- MOCRÁTICOS}

El día 11 de enero de 1923 las tropas francesas y belgas cumplieron la amenaza de invadir la cuenca minera del Ruhr, ante la imposibilidad de la República alemana de continuar con el pago de las indemnizaciones de guerra. La situación, que había sido prevista en sus congresos precedentes, volvía a poner al internacionalismo obrero ante un sombrío panorama. Las resoluciones del Congreso de la Paz y del Congreso de Roma eran claras a ese respecto: las fuerzas sindicales responderían con una convocatoria de huelga general en sus respectivos países. Los acontecimientos volverían a demostrar la débil capacidad de influencia de sus instituciones supranacionales.

A diferencia de lo que había sucedido durante la Primera Guerra Mundial, los sindicatos de inspiración socialista, belgas y franceses, esta vez en contra de sus gobiernos, emitieron resoluciones de condena. La central alemana Allgemeiner Deutsche Gewerkschaftsbund (ADGB) se opuso de forma rotunda, sin embargo, a una huelga general por considerar que sería negativa para los trabajadores alemanes.

La primera medida que el Comité de Ámsterdam y la Internacional socialista propusieron fue la solicitud de mediación por parte de la Sociedad de Naciones. La búsqueda de una solución arbitral fue apoyada por las organizaciones socialistas españolas, cuyos dirigentes se entrevistaron con el presidente del Gobierno español, García Prieto, para reclamar que el representante español en la siguiente reunión de la Sociedad de Naciones propusiera la intervención de ese organismo en la cuestión del Ruhr, en calidad de tribunal arbitral. Los líderes socialistas hicieron entrega al presidente español de una carta dirigida a su homólogo galo solicitando el restablecimiento del derecho internacional y la mediación de la Liga de las Naciones ${ }^{39}$. Rechazaban, sin embargo, cualquier inteligencia con los sindicatos rusos para dirimir el conflicto y consideraban la propuesta de apoyo que habían realizado los bolcheviques como un intento de romper la unidad de los sindicatos en el seno de la FSI.

La dirección de UGT no tenía una respuesta unánime sobre la posibilidad de plantear una huelga general de condena: Saborit y Cordero estimaban que UGT podía responsabilizarse del éxito de una huelga de 24 horas. Trifón Gómez, Lucio Martínez y Luis Fernández eran más cautos. Caballero y Besteiro se mostraron partidarios de hacer comprender a la FSI que la convocatoria del paro en España entrañaba un serio riesgo de fracaso. Estaban de acuer-

39 Acta de la reunión de la CE del Comité Nacional de UGT, 23-01-1923, FPI, AARD, 253-2. Acta de la reunión del Comité Nacional de UGT, 27-01-1923, FPI, AARD, 259-1. «Momentos difíciles. Por la amnistía y contra la guerra. El Partido Socialista y la UGT visitan al jefe del Gobierno», El Socialista, 23-01-1923: 1. 
do, sin embargo, en no alentar un entendimiento con CNT para convocar una huelga de esas características ${ }^{40}$. La resolución de los problemas internacionales debía plantearse en clave socialista: buscar el acercamiento a fuerzas de izquierdas pero antagónicas solo empeoraría la situación.

Finalmente, la FSI se declaró incapaz para convocar un movimiento huelguístico internacional y se limitó a solicitar medidas arbitrales por parte de la Sociedad de Naciones. La ocupación de la cuenca del Ruhr generó, además, una división interna en la dirección, sobre la relación con Moscú y sus adláteres y la creación de un frente único, que solo apoyó Fimmen. La crisis reforzó la idea de que, a pesar de sus millones de afiliados, la FSI no tenía instrumentos para detener una agresión o una guerra y volvió a abrir la herida de la división comunista.

La década de los años veinte fue el comienzo de la nueva etapa caracterizada por el avance del totalitarismo. Ante la impotencia de los organismos internacionales, se instauraron los regímenes de Horthy en Hungría, Mussolini en Italia y Primo de Rivera en España. Como respuesta, la FSI y sus organizaciones afiliadas respondieron con acciones de diversa intensidad.

Cuando Miklos Horty se hizo con el poder, la FSI emprendió una campaña de rechazo. Las organizaciones sindicales y políticas socialistas húngaras, ya refugiadas en Austria y Alemania, lanzaron la primera llamada de auxilio ante el Buró de la FSI, pidiendo socorro financiero y material ${ }^{41}$. Como consecuencia, la Internacional planteó, en el verano de 1920, solo un año después de su reconstrucción, un llamamiento al boicot industrial contra los productos húngaros $^{42}$, que se iba a convertir en una de sus operaciones estrella, junto al boicot al suministro de armas a Polonia.

La resolución a favor del boicot, adoptada en la reunión de la FSI de mayo de 1920, representaba un hito en la historia del internacionalismo, ya que hasta ese momento, los sindicatos nunca habían dirigido una acción internacional contra un Estado ${ }^{43}$.

A comienzos de junio, UGT recibía la comunicación de la FSI por la que se declaraba «el boicot a Hungría, en vista del proceder sanguinario y despótico de los gobernantes de aquel país, esperando se haga cuanto se pueda en

40 Acta de la reunión del Comité Nacional de UGT, 27-01-1923, FPI, AARD, 259-1.

41 «Premier rapport sur l'activité de la Federation Syndicale Internationale (juillet 1919décembre 1921), presenté au Congrès ordinaire de Rome, abril 1922», Le mouvement syndical international, suplément V, abril 1922: 37, IISH.

42 El propio Edo Fimmen se congratulaba de la suplantación de las funciones de la Sociedad de Naciones por una FSI mucho más activa que ese organismo. FIMMEN, 1922: 12.

43 «Premier rapport sur l'activité de la Federation Syndicale Internationale (juillet 1919décembre 1921), presenté au Congrès ordinaire de Rome, abril 1922», Le mouvement syndical international, suplément V, abril 1922: 41, IISH. 
este sentido» ${ }^{44}$. Los obreros españoles eran conminados a no consumir las mercancías húngaras. La carta de la FSI por la que se anunciaba el boicot fue retenida por el Gobierno español, motivo por el cual UGT formalizó una protesta ante el presidente Dato ${ }^{45}$. España asumió de buen grado el boicot, que consideraba como el arma decisiva en manos del sindicalismo internacional, en pugna contra gobiernos autoritarios.

El Gobierno húngaro, que tenía especiales dificultades para el abastecimiento energético, se puso en contacto con la FSI para exigir el fin del boicot. Días más tarde, el primer ministro presentaba su dimisión. Los líderes de la FSI lo consideraron un triunfo de la acción internacional y publicaron en todos los países la valoración que el embajador húngaro en Viena había hecho de la situación: «Si hoy derriba el Comité de Ámsterdam al gobierno de Hungría, mañana derribará al de Lloyd George y al de Millerand y se convertirá en la dictadura para todos los gobiernos europeos...» ${ }^{46}$.

Aunque el objetivo último, la expulsión de Horthy del Gobierno, no se había materializado, la operación de boicot de las organizaciones sindicales mundiales fue considerada un éxito. El balance fue positivo porque «cuando menos, ha logrado contener al gobierno y modificar sus bárbaros procedimientos $\rangle^{47}$.

Era la primera vez que la Internacional sindical desarrollaba un esfuerzo combativo frente a un estado que hubiera debido encabezar la internacional política.

Pero a partir de esas primeras movilizaciones, la FSI no volvió a ocuparse del régimen de Horthy en profundidad. Las prioridades estaban virando hacia otros países centrales en el mapa del poder europeo.

El ascenso del fascismo en Italia no suscitó, en principio, las mismas reacciones por parte de la FSI ni de sus uniones nacionales afiliadas. La situación previa, el acercamiento de la Confederazione Generale del Lavoro (CGdL) a las posiciones revolucionarias y la moderada influencia que el sindicalismo italiano tenía en el espacio internacional hicieron que las agresiones fascistas no tuvieran una fuerte contestación internacional.

Con el Partido Socialista Italiano roto tras sucesivas escisiones, en 1922, la CGdL era la mayor de las organizaciones obreras italianas. En 1925, agrupaba a 2.150 .000 afiliados. Sin embargo, el sindicalismo socialista italiano no tenía un poder proporcional en la Internacional sindical, quizá porque se había

44 Acta de la reunión de la CE del Comité Nacional de UGT, 3-06-1920, FPI, AARD, 253-1.

45 Acta de la reunión de la CE del Comité Nacional de UGT, 17-06-1920, FPI, AARD, 253-1.

46 «El boicot contra Hungría. Un gran triunfo y un augurio glorioso», El Socialista, 2406-1920: 1 .

47 Acta de la reunión de la CE del Comité Nacional de UGT, 26-08-1920, FPI, AARD, 253-1. 
debatido demasiado tiempo entre la cercanía al mundo soviético o la permanencia en la FSI. Por otra parte, UGT había mantenido escasas relaciones bilaterales con la central italiana.

Tras la marcha de Roma, la Internacional no intervino para evitar las persecuciones. Temía que una fuerte intervención fuera un elemento negativo ante la posibilidad de continuar manteniendo o avanzando en las reformas ${ }^{48}$.

Como consecuencia de la persecución, la CGdL solo pudo mantener representación en el exilio francés. El asesinato del diputado socialista Mateotti se convirtió en el símbolo de las destructivas intenciones del fascismo sobre el movimiento obrero. La FSI comenzó a partir de ese momento una fructífera colaboración con la LSI ${ }^{49}$ para intentar impedir el avance del fascismo. Ambas crearon un Fondo de Solidaridad Internacional, con el nombre del diputado socialista italiano asesinado. En él se invirtieron fondos para socorrer a las organizaciones damnificadas por el totalitarismo. Pero, en la práctica, entre 1924 y 1928, la FSI prácticamente no intervino en Italia.

Cuando quiso actuar, lo único que pudo hacer fue prestar apoyo a las organizaciones obreras italianas en el exilio. En 1926, la Internacional decidió establecer una cuota prácticamente obligatoria, en función del número de afiliados de cada central nacional, para financiar al sindicalismo italiano clandestino. España se sumó al esfuerzo, con una cantidad de 438 florines holandeses, que, según los dirigentes ugetistas, constituía un verdadero sacrificio para la Unión ${ }^{50}$.

La FSI había reaccionado tarde pero las centrales nacionales también fueron reacias a rectificar una posición inicial desafortunada. Tras conocer que los sindicatos italianos tenían la totalidad de su estructura en el exilio, las respuestas no fueron unánimes. UGT se posicionó afirmando «que la ejecutiva lamenta mucho la situación de los compañeros italianos, pero que considera ineficaz la ayuda económica por el momento y que la reserva para cuando se puedan reorganizar los sindicatos en la misma Italia» ${ }^{51}$. Y se sumó al rechazo mayoritario del Buró de la FSI de una nueva proposición del secretario general para financiar con 250 florines holandeses mensuales el centro del movimiento sindical italiano en París ${ }^{52}$.

UGT había emitido una resolución condenando el fascismo en su XV congreso, celebrado en el año 1923, solidarizándose con los compañeros de la

48 VAN GOETHEM, 2006: 195.

49 La internacional política que surgió de la fusión de la Segunda Internacional Socialista y la Unión de Partidos para la Acción Internacional (Internacional Dos y Media, con sede en Viena) en 1923 será citada en adelante indistintamente con las siglas franco-españolas (Internacional Obrera y Socialista, IOS) o con sus siglas inglesas (Labour and Socialist Internationa, LSI).

50 Acta de la reunión de la CE de UGT, 23-11-1926, FPI, AARD, 254-1.

51 Acta de la reunión de la CE de UGT, 15-03-1927, FPI, AARD, 254-2.

52 Acta de la reunión de la CE de UGT, 10-04-1928, FPI, AARD, 254-3. 
Confederazione Generale del Lavoro ${ }^{53}$. En la IX sesión de la Conferencia Internacional del Trabajo, celebrada en 1926, Largo Caballero, como miembro de la Comisión de verificación de poderes a la conferencia, en nombre de la representación obrera emitió un «informe de la minoría», en el que se oponía a la aceptación de poderes del que había sido nombrado delegado obrero de Italia, Rossini, al considerar que no representaba al sindicalismo libre italiano, sino más bien era un ejemplo claro de la situación de ventaja que los sindicatos fascistas habían adquirido ante el control sindical gubernamental. El Gobierno italiano había permitido que las corporaciones fascistas absorbieran los 2.150.000 militantes de la CGdL, los 1.183.000 de la Confederación Italiana del Trabajo y los 500.000 de la Unión Sindical Italiana. Caballero denunció también las acciones violentas contra el movimiento obrero, hasta lograr la hegemonía fascista entre los obreros italianos ${ }^{54}$.

Sin embargo, UGT se mostró poco diligente a la hora de auxiliar a los sindicatos italianos, demasiado condicionada por su falta de recursos y por el pasado filocomunista de la central sindical hermana. En general, la situación italiana no desató la alarma suficiente entre los integrantes del movimiento obrero internacional y tampoco en la organización socialista española.

En septiembre de 1923 Primo de Rivera se hizo con el poder en España mediante un golpe de Estado. El dictador fue consciente de que para contar con el apoyo de la patronal catalana tenía que neutralizar a la CNT y su estrategia terrorista. Cualquier perjuicio a UGT podía traer problemas más graves, ya que el sindicato socialista se hallaba representado y defendido en dos grandes organizaciones internacionales: contaba con la protección de la FSI, que no iba a permanecer pasiva ante cualquier agresión; y tenía un papel importante en la OIT, consolidado a través del trabajo de Largo Caballero.

Antes de posicionarse ante la naciente dictadura, UGT tuvo en cuenta diversas consideraciones como la necesidad de profundizar los avances en materia laboral o la de beneficiarse de la neutralización de su central sindical competidora, la CNT. Pero en su decisión tuvo una gran influencia el ofrecimiento del directorio militar, apenas unos días después del pronunciamiento, para continuar siendo la central representante obrera ante la OIT.

Tras conocer el golpe de Estado en España, la FSI se dirigió a la Comisión Ejecutiva de UGT para ofrecer la colaboración que la central española pudiese necesitar. UGT se comprometió a mantener informada a la Internacional ${ }^{55}$, pero en ningún momento se planteó hacer uso de esta ayuda. Por el contrario,

53 «Contra el fascismo», El Socialista, 1-02-1923: 5.

54 «Discurso de Largo Caballero en la IX Sesión de la Conferencia Internacional del Trabajo, 1926», en CUESTA, 1997: 259-262.

55 Actas de la reunión de la CE del Comité Nacional de UGT, 27-09-1923 y 2-11-1923, FPI, AARD, 253-2. 
sus informes sobre la situación que se vivía en España fueron tranquilizadores, sobre todo a medida que avanzaba su consolidación como única central permitida por la dictadura.

Ni el Buró de la FSI ni los sindicatos afiliados de otros países hicieron una crítica a la posición de UGT en relación con la dictadura. Por el contrario, la Internacional consideraba que la pertenencia de UGT a la FSI iba a producir un efecto moderador sobre el gobierno dictatorial. Amenazó con su posible intervención ante cualquier intento de agresión a su central afiliada y prometió mantenerse expectante ${ }^{56}$.

Fue la propia UGT quien impidió una condena abierta del régimen corporativo de Primo de Rivera. La Internacional, empeñada en una lucha contra la reacción y pronto también de forma explícita contra el fascismo, recibió la información de lo que sucedía en España siempre a través de UGT y, en consecuencia, tuvo la percepción de que las clases trabajadoras podían obtener más recompensas permaneciendo en la lucha sindical activa que absteniéndose de participar, aun a costa de hacerlo bajo un régimen no democrático. Las referencias de la FSI a la situación en España siempre fueron mínimas y respetaron la decisión de UGT, sin cuestionar su acierto o legitimidad.

Por su parte, la participación de los ugetistas en la OIT fue clave: los líderes del sindicato socialista español no deseaban abandonar la representación, motivo por el cual el ofrecimiento del Gobierno dictatorial fue decisivo.

Durante la dictadura, por influencia del laborismo británico, se constituyó un comité de coordinación entre PSOE y UGT. Este comité desarrolló su acción entre los años 1924 y 1927, inspirado en la experiencia del modelo laborista británico ${ }^{57}$. Significaba un paso más allá en la politización de UGT, que, según algunos autores, llegó a suplantar al PSOE en su papel político ante el nuevo régimen ${ }^{58}$.

En 1924, la etapa de reflexión había concluido. UGT participó en la reunión del Consejo de Administración de la OIT en Ginebra, con la asistencia de Largo Caballero ${ }^{59}$. En la reunión se debatió sobre la posibilidad de que la siguiente conferencia de la OIT se celebrara en España. UGT hizo constar al Grupo Obrero que «hasta ahora el Directorio no se había conducido en relación con la organización obrera en condiciones distintas que cualquiera de los gobiernos civiles anteriores y que el estado de ánimo de los trabajadores en relación con la Oficina nunca había sido mejor». Sin embargo, el Grupo acordó por unanimidad que si se hacía esa propuesta, en la que el representante

56 L'Oeuvre de la Fédération Syndicale Internationale dans les années 1922-1924, Ámsterdam, IISH, FSI, 1924: 83.

57 MARTÍN RAMOS, 2008: 152.

58 GÓMEZ-NAVARRO, 1991: 433-444.

59 Acta de la reunión de la CE de UGT, 19-01-1924, FPI, AARD, 253-3. 
gubernamental español estaba muy interesado, sus miembros votarían en contra «ya que no hay libertad de prensa ni de palabra y se vive un régimen de dictadura ${ }^{60}$.

En 1924 se planteó una visita oficial del director de la OIT a España. Aunque en principio se habían manifestado a favor del viaje, los dirigentes de UGT reconsideraron su posición y se opusieron al viaje de Thomas a España ${ }^{61}$. Temían que el Gobierno dictatorial capitalizara la visita.

Finalmente, fue imposible modificar el plan que ya se había tramitado. Los dirigentes de UGT se esforzaron, entonces, en evitar que el viaje se convirtiera en un refrendo de las políticas del gabinete de Primo de Rivera. Albert Thomas se aprestó a colaborar. Su visita tenía como objetivo fundamental analizar la situación en la que se encontraban las organizaciones sindicales y la legislación social $^{62}$. Thomas se encontró en España con los dirigentes ugetistas, que se preparaban para asistir al congreso de Viena de la FSI, y es muy probable que instara a los líderes a continuar encabezando la representación obrera española ante la OIT, así como a perseverar en la consecución de una avanzada legislación social. La visita de Thomas a España contribuyó a que los socialistas consolidaran su participación en todos los puestos de representación obrera que el régimen de Primo de Rivera les permitió seguir ocupando ${ }^{63}$.

La OIT no perdió de vista la relación de UGT con los organismos del régimen. El debate interno que PSOE y UGT desencadenaron a propósito de la conveniencia de aceptar el nombramiento de Largo Caballero como miembro del refundado Consejo de Estado, en octubre de 1924, fue seguido con suma atención por la OIT que, dicho sea de paso, respetó escrupulosamente la posición de todas las partes. No hubo intervención en ningún sentido, aunque se contemplaron con interés las posiciones enfrentadas que iban surgiendo dentro del socialismo español, sobre todo a raíz de la dimisión de Indalecio Prieto de la ejecutiva del $\mathrm{PSOE}^{64}$. Por el contrario, la influencia de Fabra Ribas sobre Albert Thomas fue decisiva a la hora de interpretar la posición de UGT. Fabra Ribas se encargó de trasladar a la OIT la opinión de que la aceptación del nombramiento como consejero de Estado permitía a los socialistas continuar defendiendo los intereses de la clase obrera frente a representantes de otros sectores sociales y corporaciones ${ }^{65}$.

60 Acta de la reunión de la CE de UGT, 5-02-1924, FPI, AARD, 253-3.

${ }_{61}$ Acta de la reunión de la CE de UGT, 22-04-1924, FPI, AARD, 253-3.

62 Diversos documentos «OIT. Gabinete A. Thomas. Viaje a España 1924», FPI, AAVV, CI-8.

63 GÓMEZ-NAVARRO, 1991: 433-444.

64 «Note pour M. Le Directeur. Espagne. La reunión pleinière du parti socialiste discute la représentation ouvrière dans le Conseil d'Etat», 19-12-1924, FPI, AAVV, CI-4, folio 66-68.

65 Carta de Antonio Fabra Ribas a Albert Thomas, 24-11-1924, FPI, AAVV, CII-9, folio 125. 
En noviembre de 1926, el régimen creó la Organización Corporativa Nacional para regular las relaciones laborales, muy influida por el corporativismo fascista italiano. La OIT recabó, entonces, la opinión de UGT a través de su representante en España. Fabra trasladó a Thomas que UGT consideraba que el decreto ley tenía el defecto de origen de no haber sido sancionado por ningún parlamento, pero examinando su contenido pensaban que, si se aplicaba de forma estricta, «representaría un progreso tan evidente que podría incluso llegar a cambiar la estructura social de nuestro país. Pero al mismo tiempo, temen que en la práctica se encontrarán dificultades para hacerlo efectivo y que esas dificultades no procederán de los elementos de la Unión General de Trabajadores sino del Partido Socialista» ${ }^{66}$. El propio Albert Thomas, aunque adoptó una posición prudente hasta conocer la totalidad del decreto, atenuó las críticas que dentro de su propio gabinete había recibido el proyecto, comparando algunos aspectos de la nueva organización con los consejos de Prud'hommes de Francia, que nunca habían suscitado tanto rechazo ${ }^{67}$.

La OIT se mantuvo alerta ante la posibilidad de que el régimen tratara de beneficiar a la organización obrera que la dictadura había alentado activamente, a instancias de su ministro de la Gobernación, general Martínez Anido: los sindicatos libres ${ }^{68}$.

Lo que reflejaban los informes de la OIT respecto a la cuestión de los sindicatos libres era un enfrentamiento entre dos concepciones sindicales en el seno del gobierno: Martínez Anido encarnaba la posición de los partidarios de destruir las fórmulas tradicionales de organización obrera, alentando la ampliación de las bases sociales de los sindicatos libres o directamente utilizando los métodos violentos que tan buenos resultados habían dado contra la CNT en Barcelona; Primo de Rivera era partidario, por el contrario, de beneficiar a UGT y avanzar en las medidas de carácter social, como método de control de una enorme masa de trabajadores que, de lo contrario, podía convertirse en beligerante contra el régimen. De momento, y a pesar del hostigamiento que UGT podía sufrir en sus bases, en la cúpula prevalecía la idea del general Primo de Rivera, frente a la del también general Martínez Anido.

El temor de los hombres de la OIT —incluido Albert Thomas- era que el rechazo de UGT a secundar alguno de los importantes proyectos políticos de la dictadura hiciera prevalecer la posición de Anido sobre la de Primo. La mayor preocupación era la posición que los socialistas podían tomar ante el proyecto de Asamblea Nacional. El dictador expuso su proyecto en 1927, esforzándose por atraer a la Unión. La propuesta marcó un nuevo tiempo en

${ }^{66}$ Informe de J. Bueno al director de la OIT sobre la situación en España, 16-12-1926, FPI, AAVV, CI-5, folios 97-104.

67 Comunicación de Albert Thomas a M. Bueno, 14-12-1926, FPI, AAVV, CI-5, folio 96.

68 GÓMEZ-NAVARRO, 1991: 444-453. ELORZA, 1971: 141-413. 
las relaciones entre el sindicato socialista y el dictador. Sectores importantes del sindicato comenzaban a cuestionarse la necesidad de una ruptura definitiva de la colaboración. La convocatoria de un congreso extraordinario de UGT en 1927 para dirimir esta cuestión provocó inquietud en la OIT, que se manifestó partidaria de la continuidad de la colaboración de UGT con el Gobierno dictatorial. Si los dirigentes ugetistas se negaban a participar en la Asamblea, los sindicatos libres, con el respaldo de un gobierno ahora volcado hacia las tesis del ministro de la Gobernación, se convertirían en la fuerza más importante en el terreno sindical y en representantes reconocidos de la clase obrera organizada ${ }^{69}$. En consecuencia, los informes internos de la OIT, sin manifestarse de forma expresa en contra de la decisión adoptada en congreso extraordinario por UGT de no participar en la Asamblea, destilaban un manifiesto tono crítico con la posición, de la que hacían responsable a Indalecio Prieto.

No se agotaban ahí sus preocupaciones. En 1926 España había anunciado la retirada de la Sociedad de Naciones, lo que podía suponer una retirada en paralelo de su agencia especializada para el trabajo. Thomas se volcó en evitarlo, a pesar de la evidencia de un cada vez mayor acercamiento entre el gobierno español y el italiano.

En 1927 se producía, además, un nuevo hito que consolidaba la posición de UGT en el mundo internacional. Como consecuencia de la dimisión del dirigente de la CGdL italiana, d'Aragona, del cargo de vocal obrero suplente del consejo de administración de la OIT, Largo Caballero pasó a ocupar dicho puesto $^{70}$.

Cuando UGT ratificó su ruptura con el régimen, su pertenencia a los organismos internacionales y el prestigio que los ugetistas mantenían en la OIT -a pesar de que su dirección no estuvo del todo de acuerdo-, constituyeron una valiosa protección para el sindicato socialista.

\section{UNA REPÚBLICA PARA LOS TRABAJADORES}

En 1929, UGT abandonó la participación en los organismos del régimen de Primo de Rivera, no sin disputas en el seno de su dirección. A partir de ese momento, era aún más importante contar con el apoyo internacional en ese nuevo camino. Después de la reunión del consejo general de la FSI en Praga en mayo de 1929, los líderes españoles solicitaron formalmente que la siguiente reunión del consejo se celebrara en Madrid, bajo el padrinazgo de

69 Informe de J. Bueno «Note pour M. le directeur. Le développement et l'importance des syndicats libres en Espagne», 28-09-1927, FPI, AAVV, CI-6, folios 43-48.

70 Acta de la reunión de la CE de UGT, 10-05-1927, FPI, AARD, 254-2. 
$\mathrm{UGT}^{71}$. La FSI puso especial interés por reforzar la posición de UGT en el interior de España y en el concierto internacional, programando su reunión en la capital española. Pero las difíciles circunstancias que vivía el país obligaron a posponer el encuentro en varias ocasiones.

En diciembre de 1930, su implicación en el movimiento antimonárquico condujo a muchos militantes socialistas hasta la cárcel. La mayor parte de la Ejecutiva ugetista se encontraba en prisión en los primeros meses de 1931. A pesar de que había voces internas en contra, FSI mantuvo la convocatoria de reunión del consejo general en España. Cuando llegó la fecha del encuentro, Madrid era ya la capital de un país republicano y el primer representante de UGT en los organismos oficiales, Francisco Largo Caballero, su ministro de Trabajo.

El 27 de abril de 1931, el consejo general de la FSI se reunía en Madrid, apenas unos días después de la proclamación de la República. Francisco Largo Caballero hacía un breve resumen de la nueva situación. El país constituía, en ese momento, una isla de ilusiones para los socialistas de una Europa cada vez más amenazada por la crisis económica, los nacionalismos exacerbados y el fascismo. Émile Vandervelde, en su calidad de presidente de la IOS, dirigió un discurso en el que hacía mención de la ingente tarea que tenía delante la Internacional sindical: desde trabajar por una legislación de protección obrera hasta constituirse en un organismo garante de la paz ${ }^{72}$.

Eran tiempos de cambios. La FSI llevaba varios meses valorando la posibilidad de trasladar su sede y de renovar los cargos directivos. UGT apostó por mantener la sede en Ámsterdam, por considerar que el resto de ciudades que se estaban manejando plantearían mayores problemas. En 1928, Largo Caballero había llevado a la reunión del consejo general la propuesta de mantener Ámsterdam como sede y las candidaturas de Walter Citrine para la Presidencia y J. Sassenbach para la Secretaría General ${ }^{73}$.

Sin embargo, la decisión final que se adoptó en el Congreso de la FSI celebrado en Estocolmo en 1930 fue trasladar su sede a Berlín. La medida había tenido una fuerte oposición interna, fundada en la amenaza del avance del nazismo en Alemania, lo que podía complicar el desarrollo normal del trabajo de la Internacional. La decisión se ejecutó en firme el 1 de julio de 1931. Las consecuencias iban a ser devastadoras.

En pleno auge del fascismo en diversos países de Europa, el análisis que el sindicalismo internacional hizo de la situación puede explicar algunas claves de política interior, entre ellas, la radicalización de la acción sindical de UGT durante el bienio negro.

\footnotetext{
71 Acta de la reunión de la CE de UGT, 4-07-1929, FPI, AARD, 255-1.

72 «La Federación Sindical Internacional», El Socialista, 28 y 29 abril 1931: 4.

73 Acta de la reunión de la CE de UGT, 14-08-1928, FPI, AARD, 254-3.
} 
Desde comienzos de la década de los años treinta, tanto la FSI como la Internacional del Transporte (ITF) habían ofrecido la ayuda necesaria a los sindicatos alemanes para organizar la lucha contra los nazis. La FSI auspició varias reuniones entre su comité ejecutivo, su secretario general y los jefes responsables de los sindicatos alemanes, para organizar la resistencia sindical contra el avance de las agresiones nazis. Elaboraron un plan de apoyo financiero y militar, con abastecimiento de armas para la defensa en las luchas callejeras y un plan político global. Trataban de rectificar así los errores que habían cometido en el caso italiano. Pero los sindicatos alemanes no aceptaron. Sostenían que esa lucha no debía trascender al medio internacional, porque podría contribuir a eliminar los pocos espacios de libertad sindical que aún quedaban en el país. Desde que Hitler llegó a la Cancillería, se hizo imposible el funcionamiento del Secretariado en Alemania. En la reunión del buró del 30 de abril de 1933 se tomó la decisión de trasladar la sede del FSI de Berlín a París ${ }^{74}$.

Las organizaciones obreras alemanas tuvieron dudas respecto a la estrategia a seguir para evitar su total destrucción, pero en última instancia eligieron una línea conservadora. La FSI fue respetuosa con estas intenciones, a pesar de que en su seno hubo organizaciones que apostaron por adoptar las medidas más coercitivas que tenía en su poder la Internacional. Así, en mayo de 1933, la central holandesa proponía un boicot para contrarrestar las medidas del gobierno de Hitler que acorralaban a las organizaciones obreras. UGT se opuso a desencadenar el boicot, considerando la posibilidad de que la situación terminara perjudicando en mayor medida a los trabajadores que al gobierno ${ }^{75}$. Sería la propia posición de la central alemana la que evitaría una intervención más dura por parte de la FSI. Por otra parte, UGT se decantó por rechazar los ofrecimientos que los sindicatos rusos y el Socorro Rojo Internacional plantearon para organizar la intervención en el asunto alemán ${ }^{76}$. Finalmente, la FSI, en la reunión de su consejo general celebrado en 1933 acordó el boicot a los productos industriales alemanes, que fue ratificado en el congreso de la FSI celebrado ese mismo año en Bruselas ${ }^{77}$. Las consecuencias del boicot fueron, sin embargo, nulas.

La llegada de Dollfuss a la cancillería y su proyecto de acabar con el poder y la influencia sindical habían sido contestados por los sindicatos austriacos con la preparación de un plan de revolución para apartar a los pronazis del poder. FSI e ITF prestaron una enorme ayuda a los austriacos. El plan era

74 SCHEVENELS, 1964: 121-124.

75 Acta de la reunión de la CE de UGT, 11-05-1933, FPI, AARD, 256-2.

76 Acta de la reunión de la CE de UGT, 10-08-1933, FPI, AARD, 256-2.

77 L'oeuvre de la Federation Syndicale Internationale, 1933-1935, París, FSI, 1937: 130131, IISH. 
proclamar la huelga general, seguida de la toma de todos los puntos estratégicos del poder en Viena. En pocos días la práctica totalidad de Austria estaría en manos de las fuerzas obreras libres. Antes de ejecutar el plan hubo un intento por parte del secretario general de la FSI, Walter Schevenels, de entrevistarse con Dollfuss, el 3 de febrero de 1934. Pero Dollfuss envió a la reunión al secretario permanente de la Cancillería, el ministro Hornbostel. La entrevista convenció a Schevenels de que el gobierno austríaco estaba decidido a aniquilar el movimiento obrero. Ese mismo día eran detenidos los principales dirigentes sindicales y el combate se extendió por las calles de Viena. El 14 de febrero, Schevenels volvió a Viena, llevando 50.000 chelines para socorrer a los sublevados y a sus familias.

En adelante, la FSI no pudo hacer más que apoyar la reconstrucción de un movimiento sindical clandestino. La dirección de UGT, a diferencia de algunos sindicatos de ramo que la componían, consideró inoperante la declaración de una huelga general en solidaridad con los compañeros austriacos. Sin embargo, hizo fuertes desembolsos económicos, en una situación muy complicada, para apoyar a los sindicalistas de ese país ${ }^{78}$.

La situación internacional y sobre todo lo sucedido en Austria condicionaron el análisis que los dirigentes sindicales hicieron sobre la coyuntura española, tras el triunfo de los partidos de derechas, en las elecciones de 1933. La mayoría de la historiografía ha volcado el peso del análisis sobre las cuestiones nacionales a la hora de explicar la posición de UGT y, concretamente, de su líder, Largo Caballero, en la preparación y desarrollo de la revolución de octubre de 1934. Pero la situación europea no fue ajena a la decisión de lanzar el movimiento revolucionario.

Largo Caballero evocaba en su discurso en el VII Congreso de la FSI, celebrado en Londres en 1936, las causas que habían llevado a la clase obrera a levantarse contra el poder establecido, invocando el espíritu de responsabilidad de la UGT, que había realizado «su misión histórica, cumpliendo los mandatos constantes de la Internacional, que recomendaba luchar contra el fascismo (...). Tenemos que decir que al producirnos así, no lo hacemos por espíritu egoísta y nacional. La clase trabajadora española, cuando va a esos movimientos, lo hace en un sentido eminentemente internacional, con el fin de impedir que el fascismo se entronice en nuestro país» ${ }^{79}$.

Queda la duda de si la FSI financió previamente el movimiento revolucionario español, como sí lo hizo — según reconocieron sus propios líderes-, en Austria. El 3 de octubre de 1934, tan solo un día antes de que entraran en el Gobierno tres ministros de la CEDA, la Ejecutiva de la FSI dirigió un tele-

78 Acta de la reunión de la CE de UGT, 6-09-1934, FPI, AARD, 256-3.

79 «Discurso de Francisco Largo Caballero en el mitin de la FSI en Londres», Claridad, 10-07-1936.

Hispania, 2018, vol. LXXVIII, $\mathrm{n}^{\circ}$. 259, mayo-agosto, págs. 323-352, ISSN: 0018-2141, e-ISSN: 1988-8368 https://doi.org/10.3989/hispania.2018.008 
grama al presidente de la República pidiéndole que no admitiera a los fascistas en el Gobierno y devolviera a España por el camino de la democracia. No obtuvieron respuesta.

Ya durante la lucha, Schevenels volvió a Madrid para entrevistarse en la capital con algunos líderes sindicales que aún estaban en libertad. Se puso en marcha un plan de ayuda para las víctimas españolas y para los militantes en prisión y sus familias ${ }^{80}$.

Cuando finalizaron los combates, el Buró envió un telegrama de protesta al presidente la República por las represalias ejercidas por la policía y el ejército y, al mismo tiempo, hizo su primer envío de dinero. El comité se reunió en París en noviembre de ese mismo año para evaluar la situación en España. El análisis se realizó en común con la IOS y el resultado fue la publicación de un comunicado. En él acusaban al Gobierno español de querer explotar la situación para suprimir las libertades y los derechos obreros y preparar un sistema de corporaciones fascistas. El comunicado exhortaba al gobierno a acabar con las detenciones y las ejecuciones.

Por su parte, Jouhaux y Mertens, en nombre del Grupo Obrero de la OIT, condenaron la situación en la que se encontraba Largo Caballero, impedido para cumplir con su mandato internacional por hallarse encarcelado. El 16 de noviembre, la FSI y la IOS dirigieron un telegrama protestando contra la falta de respeto a la inmunidad parlamentaria de Largo Caballero y Teodomiro Menéndez.

En diciembre de 1934, se conformó un comité mixto especial destinado a España, constituido por Auriol (en nombre de la IOS), el presidente de la Liga de los Derechos del Hombre y Schevenels, en nombre de la FSI. UGT nombró su representante a Julio Álvarez del Vayo para entrevistarse con Schevenels y hacerse cargo del dinero recolectado en París, comprometiéndose a destinar el 20\% de lo recaudado para paliar la situación de los refugiados españoles en Francia y Bélgica ${ }^{81}$.

En la reunión que el Buró de la FSI celebró entre el 15 y el 16 de enero de 1935 la cuestión española fue protagonista. En paralelo, el Socorro Rojo Internacional de Moscú se dirigió a la FSI, a la IOS y al Fondo Matteoti para proponer una acción coordinada de socorro a España. En la reunión se valoró esta propuesta, pero el Buró de la FSI, de acuerdo con la IOS, acordó declinar el ofrecimiento.

Era prioritario desarrollar un plan de socorro y de protección jurídica. La FSI tomó la decisión de enviar una comisión mixta, integrada por su secretario general, Walter Schevenels, un representante de la Liga de los Derechos del Hombre y un representante de la IOS, así como un abogado británico,

80 SCHEVENELS, 1964: 132-133.

81 Acta de la reunión de la CE de UGT, 27-12-1934, FPI, AARD, 256-3. 
para hacer una gestión oficial ante los presidentes de la República y del gobierno. Llegaron a España Vicente Auriol, y Schevenels. La comisión consiguió hacerse recibir por el presidente Lerroux, que garantizó que España no derivaría en un Estado fascista bajo su presidencia y que intervendría personalmente para que se atenuaran los «rigores de la ley». El presidente de la República, Niceto Alcalá Zamora, no recibió a la Comisión.

Cuando se conocieron las condenas a muerte recaídas sobre Teodomiro Menéndez y González Peña, la FSI, la IOS y la Liga de los Derechos Humanos enviaron un telegrama solicitando a los presidentes de la República y del gobierno el indulto para los dos condenados y, al mismo tiempo, pusieron en marcha una campaña internacional en la que movilizaron a todas las organizaciones afiliadas para presionar sobre el Ejecutivo y evitar la condena.

En paralelo, la FSI destinó una serie de iniciativas a favor de los refugiados españoles que abandonaron España a través de los Pirineos. La primera acción fue desarrollada por la Confederación General del Trabajo (CGT) de Francia, en coordinación con la FSI, para asistir a los 150 o 200 refugiados que llegaron a Francia después de la derrota ${ }^{82}$.

Sin embargo, la propia FSI reconoció que, a pesar de todos sus esfuerzos, la ayuda económica enviada a España fue menor de lo que sus dirigentes hubieran deseado. Adujeron como atenuante el sobreesfuerzo que las organizaciones afiliadas venían realizando para intervenir sobre la represión y el acoso a las organizaciones sindicales en Austria y Alemania. Además de las cantidades que el Fondo Mateotti estableció para el apoyo de los refugiados en Francia (40.000 francos franceses) y en Suiza (6.300 francos franceses), en 1935 se enviaron a España 173.801,95 francos franceses que fueron recibidos y distribuidos por la propia $\mathrm{UGT}^{83}$.

Las condenas a muerte de los socialistas no fueron ejecutadas y Largo Caballero fue absuelto. El mundo internacional obrero hizo una evaluación positiva las consecuencias de la acción revolucionaria en España: la revolución de 1934 había otorgado a nuestro país el honor de ser la única nación en la que la acción sindical había detenido al fascismo ${ }^{84}$. En Austria, en Alemania, en Italia, en Hungría las fuerzas organizadas del movimiento obrero no habían sido capaces de impedir el ascenso de los partidos fascistas al poder, pero la organización socialista española había, por el momento, conseguido evitarlo con una respuesta internacional conjunta.

82 Rapport du Secretariat sur l'activité de la Federation Syndicale Internationale du ler. Abril 1934 au 31 mars 1935, IISH, IFTU, inventario ${ }^{\circ} 94$.

83 Congrès Londres 1936...: 159 y The activities of the IFTU 1933-1935, submitted to the Seventh Ordinary Congress, London, 1936, IISH.

84 Congrès Londres 1936...: 159 y The activities of the IFTU 1933-1935, submitted to the Seventh Ordinary Congress, London, 1936: 50-52, IISH. 
La FSI criticó de modo expreso el intento de intervención de la Internacional sindical de Moscú sobre la clase obrera española, con la excusa de la ayuda a los represaliados, tras el movimiento revolucionario de 1934. UGT había rechazado en varias ocasiones la ayuda de los comunistas ${ }^{85}$.

Pese a todo, el comité de refugiados españoles de París protestó enérgicamente ante la UGT, debido al tratamiento que estaban sufriendo por parte de la Internacional, que fue reduciendo de manera progresiva la ayuda. Como consecuencia, solicitaron permiso para dirigirse a las organizaciones francesas en demanda de apoyo. La dirección de UGT no autorizó los contactos, ya que según los Estatutos era necesario que los hiciera la propia Internacional ${ }^{86}$. En cambio, sí pidió explicaciones a la FSI que manifestó los esfuerzos que tanto la propia Internacional como la CGT francesa habían realizado para socorrer a los españoles. UGT no se conformó y solicitó información de las cantidades votadas para alemanes, austriacos y españoles. El envío de la documentación por parte de la FSI no dejaba lugar a dudas de la posición que el asunto español había ocupado en la solidaridad internacional: frente a más de 3.900.000 francos para la solidaridad con Alemania y casi siete millones de francos para Austria, solo habían llegado hasta ese momento 107.000 para España. La Internacional se disculpaba de la imposibilidad de conseguir una ayuda más importante para España, debido al sobreesfuerzo que las centrales nacionales habían hecho para intervenir en Alemania y Austria ${ }^{87}$. Pero esta inequidad generó un profundo malestar en los representantes españoles.

En el congreso de la FSI en Londres que se celebró en julio de 1936, Largo Caballero recibió una emocionada ovación. España había detenido al fascismo y la Internacional reconocía su éxito. Sin embargo, el líder español no ahorró críticas a la actuación de la FSI. Denunció que la acción contra el fascismo había sido solo un ejercicio de oratoria. El apoyo a la causa española, como los mismos dirigentes reconocieron, había dejado mucho que desear. Los trabajadores españoles no habían recibido la ayuda moral y financiera que habían esperado de la FSI. Según Caballero, los combatientes españoles habían tenido la impresión de que la Internacional sindical repetía modelos imperialistas, clasificando a los países en naciones de primera y de segunda clase.

Las elecciones para el comité ejecutivo volvieron a escenificar un escaso respaldo a la posición española. Caballero optó a la elección a un cargo vacante. Se presentaba también el holandés Kupers. La victoria de este último sobre el representante de la única nación que había dado muestras de energía

85 Acta de la reunión de la CE de UGT, 17-01-1935, FPI, AARD, 257-1.

86 Acta de la reunión de la CE de UGT, 1-08-1935, FPI, AARD, 257-1.

87 Acta de la reunión de la CE de UGT, 19-09-1935, FPI, AARD, 257-1. 
en su lucha contra el fascismo fue aplastante. España perdía la oportunidad de integrarse en la dirección de la FSI, en un momento crucial de su historia ${ }^{88}$.

El Congreso de Londres encaró otros problemas que suponían una gravísima amenaza. La extrema gravedad de la situación había propiciado el viraje de la Comintern, que adoptó una nueva estrategia en relación a los problemas de Europa y el ascenso del fascismo: por primera vez, para Moscú, los enemigos directos a batir no eran los partidos socialistas y socialdemócratas de la IOS ni los sindicatos de la FSI, sino los gobiernos fascistas que se instalaban en el corazón de Europa. La central sindical noruega, afiliada a la FSI, pero con fuertes relaciones con la Internacional sindical de Moscú, propuso la apertura de negociaciones con el sindicato ruso y con la ISR para elaborar un plan de colaboración ${ }^{89}$. En España se trabajaba en el intento de la unidad del proletariado. La fusión de UGT con CNT era el nuevo objetivo, bajo los auspicios de Francisco Largo Caballero. En el Congreso de Londres, el discurso de Largo Caballero fue inequívocamente un canto a la unidad con la Federación sindical roja. Se adhería a las propuestas de los noruegos y solicitaba, ante la gravedad de la situación, que los sindicatos libres olvidaran los agravios que, desde el comienzo de su historia, los sindicatos de adscripción comunista habían infligido al movimiento obrero ${ }^{90}$.

Tan solo unos meses más tarde, el debate dentro del movimiento obrero internacional volvía a tener como protagonista a España: los acuerdos de la no intervención abrían otra dolorosa fisura.

\section{CONCLuSIONES}

El tiempo histórico que transcurre entre la Gran Guerra y la contienda civil española fue un periodo de decisiones para el movimiento obrero internacional. Los sindicatos de orientación socialdemócrata, y entre ellos UGT, se incorporaron a los organismos de regulación del mundo del trabajo que las potencias liberales organizaron al efecto de estabilizar sus economías y sociedades. UGT, que ya había iniciado esta estrategia en el ámbito nacional, cooperó con un compromiso de primer nivel en este esfuerzo internacional. Sin embargo, su situación en el tablero mundial no pasó de ser marginal. Frente a la potencia de otros grandes movimientos sindicales, apostó por consolidar su posición mediante el intento de liderar la incorporación del movimiento sindical latinoamericano a la FSI. Pero este objetivo fracasó bajo la

88 VAN GOETHEM, 2006: 53-54.

89 Proposiciones presentadas al VII Congreso de la FSI, IISH, IFTU, inventario $\mathrm{n}^{\circ} 51$.

90 Discurso de Largo Caballero en el Congreso de la FSI, Londres, julio 1936, FPI, AH, 58-38. AROCA, 2016. 
influencia de dos polos opuestos: el sindicalismo norteamericano dirigido por la AFL y la Profintern.

Es posible advertir, también, claves internacionales en las decisiones que el sindicato adoptó respecto a la dictadura de Primo de Rivera. El ofrecimiento del dictador para continuar considerando a UGT la central más representativa en los foros internacionales fue uno de los elementos que hicieron a la UGT aceptar las condiciones que imponía la dictadura. Por otra parte, la FSI y los organismos supranacionales no interfirieron en la situación española precisamente porque UGT adoptó un papel moderador y no transmitió una situación de emergencia en España. Por el contrario, los dirigentes de OIT trataron de influir sobre UGT para estabilizar su colaboración en los organismos del régimen, considerando que lo contrario redundaría en la pérdida de conquistas de la clase obrera.

En la radicalización del sindicalismo socialista durante los años 1933 y 1934 jugó un papel fundamental la situación internacional. El auge de los fascismos, los intentos fracasados por parte de la FSI para tratar de impedir su acceso al poder y la sensación de ser el nuevo objetivo a batir por parte del fascismo internacional determinaron el giro copernicano de la política socialista y especialmente ugetista durante el llamado «bienio negro». Sin embargo, la decepción se apoderó del movimiento obrero socialista español cuando, finalizado el proceso, los líderes valoraron lo que había sucedido en España y cuál había sido la intervención de los organismos supranacionales. Unos meses más tarde, al hilo de la Guerra Civil y del desarrollo de la política de no intervención, se consolidaban los malos augurios y España se convertía en nuevo elemento de fractura dentro del movimiento obrero internacional.

\section{Bibliografía}

Aroca Mohedano, Manuela, «Spain's Unión General de Trabajadores in the international context (1888-1936)», Ventunesimo Secolo, 38 (Roma, 2016): 9-33.

Becker, Marc, «Indigenous Nationalities in Ecuadorian Marxist Thougt», en Carlos Aguirre (coord.), Militantes, intelectuales y revolucionarios. Estudios sobre marxismo e izquierda en América Latina, Raleigh, Contracorriente, 2013: 229-270.

Cuesta Bustillo, Josefina, Una esperanza para los trabajadores. Las relaciones entre España y la Organización Internacional del Trabajo (1919-1939), Madrid, Consejo Económico y Social, 1994.

Cuesta Bustillo, Josefina, Francisco Largo Caballero: su compromiso internacional, Madrid, FFLC, 1997.

De los Ríos, Fernando, Mi viaje a la Rusia sovietista, Madrid, Fundación Fernando de los Ríos, 1994.

Elorza, Antonio, «Los Sindicatos Libres en España: teoría y programas», Revista del Trabajo, 35-36 (Madrid, 1971): 141-413 
Fimmen, Edo, La Fédération Syndical Internationale. Son developpement, ses buts, Ámsterdam, Publications de la Fédération Syndical Internationale, 1922.

Gómez-Navarro, José Luis, El Régimen de Primo de Rivera. Reyes, dictaduras y dictadores, Madrid, Cátedra, 1991.

Kochanski, Aleksander, «El sindicalismo latinoamericano: Materiales del archivo moscovita de la Internacional Sindical Roja», Estudios latinoamericanos, 11 (Varsovia, 1988): 249-295.

Largo Caballero, Francisco, Presente y futuro de la Unión General de Trabajadores (1888-1925), Madrid, FFLC, 1997.

Martín Nájera, Aurelio y Garrigós Fernández, Agustín (eds.), Obras completas de Largo Caballero, Barcelona, FFLC-Instituto Monsa de Ediciones, 2003.

Martín Ramos, José Luis, Entre la revolución y el reformismo, 1914-1931. Historia de la UGT, vol. 2, Madrid, Siglo XXI, 2008.

Mateos, Abdón, «El espejo imaginario. Las relaciones entre los socialistas españoles y la izquierda mexicana hasta 1982», Tzintzun. Revista de Estudios Históricos, 63 (Morelia, enero-junio 2016): 242-267.

Nin, Andreu, Las organizaciones obreras internacionales, Barcelona, Fontamara, 1978.

Pagés, Pelai, Andreu Nin: su evolución política (1911-1937), Bilbao, Zero, 1975.

Rubio, José Luis, «El oficialismo institucional: el Instituto de Cultura Hispánica», en José Luis Abellán y Antonio Monclús (coords.), El pensamiento español contemporáneo y la idea de América, Barcelona, Anthropos, 1989: 117-207.

Schevenels, Walter, Quarante cinq années. Fédération Syndicale Internationale, Bruselas, Editions de l'Institute E. Vandervelde, 1964.

Spenser, Daniela, «Historia, política e ideología fundidas en la vida de Vicente Lombardo Toledano», Desacatos, 50 (México D.F., enero-abril 2016): 70-87, versión online.

Van Goethem, Geert, The Amsterdam International: the world of the International Federation of Trade Unions, 1913-1945, Aldershot, Ashgate, 2006.

Recibido: 19/12/2016

Aceptado: 09/05/2018 